\title{
The Effects of Different Eggshell Temperatures Between Embryonic Day 10 and 18 on Broiler Performance and Susceptibility to Ascites

-Author(s)

Ipek $A^{\prime}$

Sahan $U^{\prime}$

Sozcu $A^{\prime}$

Uludag University, Faculty of Agriculture, Department of Animal Science, Bursa, 16059, Turkey

\section{nMail Address}

Corresponding author e-mail address Prof. Dr. A. Ipek

Uludag University, Faculty of Agriculture, Department of Animal Science, Bursa, 16059, Turkey

Email: aipek@uludag.edu.tr

\section{nKeywords}

Ascites, broiler, eggshell temperature, incubation.

\section{ABSTRACT}

The aim of the current study was to determine the effects of low $\left(33.3-36.7{ }^{\circ} \mathrm{C}\right)$, control $\left(37.8-38.2^{\circ} \mathrm{C}\right)$ and high $\left(38.9-40.0{ }^{\circ} \mathrm{C}\right)$ eggshell temperatures (ESTs) between days 10-18 of incubation on broiler performance and susceptibility to ascites. The effects of different ESTs on hatchling weight were significant. The highest residual yolk sac weight $(7.7 \mathrm{~g})$ and relative yolk sac weight $(18.7 \%)$ were observed in high EST group, whereas the highest yolk-free body weight $(36.22 \mathrm{~g})$ was obtained in the control group. Relative post-hatch heart weight was lower in the high EST group (0.64\%) compared with the control $(0.84 \%)$ and low $(0.88 \%)$ EST groups. At 6 weeks of age, body weights of broilers of the low, control, and high EST groups were 2172.6, $2543.9,2282.6 \mathrm{~g}$ respectively. During the 6-week life span, the feed conversion ratio of broilers in the low (1.86) and high (1.83) EST groups was significantly worse than of those in the control EST group (1.68). Higher packed cell volume (PCV) and red blood cell (RBC) values were obtained in the high EST group relative to the other groups, whereas hemoglobin $(\mathrm{Hb})$ level was lower in the control group than in the others. The relative heart weights and right ventricular to total ventricular (RV:TV) ratio for low, control, and high EST group were 0.46, 0.40, $0.37 \mathrm{~g}$ and $0.27,0.28,0.33 \%$ respectively. In conclusion, incubation length, yolk sac absorption, residual yolk sac weight, yolk-free BW, post-hatch performance, and heart, blood parameters, abdominal fluid accumulation at slaughter age are affected by changes in EST between incubation days 10 to 18 .

\section{INTRODUCTION}

Incubation is the conversion of the contents of an egg into a chicken and it is strongly affected by incubation temperature. Incubation temperature is one of the most important factors (Molenaar et al., 2011) for embryo development and survival. The temperature within the egg, i.e., embryo temperature (Meijerhof, 2009a), is particularly critical, and maintaining the correct embryonic temperature during incubation has been shown to be more important than incubator temperature settings (Hulet et al., 2007; Meijerhof, 2009b). French (2000) reported that even small temperature differences of 0.5 or $1^{\circ} \mathrm{C}$ (from 37.5 to 38.0 or $38.5^{\circ} \mathrm{C}$ ) during the period of three to 25 days of incubation can significantly affect the embryonic development of turkeys. Several studies have shown that incubation temperature influences embryo development and post-hatch performance (Lourens et al., 2005, 2007; Meijerhof, 2009b; Molenaar et al., 2011). In studies that compared normal eggshell temperatures (approximately $37.8^{\circ} \mathrm{C}$ ) to high shell temperatures $\left(38.9\right.$ to $39.5^{\circ} \mathrm{C}$ ), chick hatching weight was lower when eggs were incubated at high eggshell temperature at the end of incubation (Lourens et al., 2005; Joseph et al., 2006; Leksrisompong 
et al., 2009). Hence, controlling embryo temperatures rather than incubator temperatures improves chick quality (Hulet et al., 2007; Meijerhof, 2009b).

Wineland et al. (2000a, 2000b) demonstrated that incubation temperatures above $37^{\circ} \mathrm{C}$ negatively affected the development of the whole body and specific organs of chickens. High incubation temperatures decrease in $17-31 \%$ the relative heart weight of broilers (Wineland et al., 2000a, 2000b; Leksrisompong et al., 2007, Lourens et al., 2008).

High incubation temperatures may cause metabolic disorders are associated with cardiovascular development, such as ascites (Molenaar et al., 2011). Ascites is a multi-factorial syndrome caused by interactions between physiological (e.g., oxygen demand, rapid growth, etc.) environmental (e.g., high eggshell temperatures during incubation, altitude, low ambient temperatures, etc.) (Yahav et al., 1997), and management (e.g., ventilation, disease status) factors (Altan et al., 2006; Ipek \& Sahan, 2006; Sahan et al., 2006). Although the peak incidence of ascites occurs in the $5^{\text {th }}$ or $6^{\text {th }}$ week of the growing period, the etiology of the disease may be initiated much earlier, even during the embryonic stage (Coleman \& Coleman, 1991).

During the development of ascites, packed cell volume (PCV), red blood cell counts $(R B C)$, and hemoglobin levels $(\mathrm{Hb})$ increase (Yersin et al., 1992). High PCV increasses blood viscosity and leads to pulmonary hypertension, right ventricular hypertrophy, edema, and ascites (Wideman 2001). The parameters $\mathrm{RV}$ :TV ratio, $\mathrm{Hb}$ level, PCV, and specific clinical chemistry parameters can be used to determine the ascites status of a bird prior to the appearance of gross lesions (Huchzermeyer, 1988).

Studies on this subject have usually compared the effects of lower or higher eggshell temperatures with optimal temperatures during early (4-7 days) (Shim \& Pesti, 2011; Joseph et al., 2006) or late incubation (18-21 days) stages (Hulet et al., 2007; Leksrisompong et al., 2007; Willemsen et al., 2010) on different parameters (e.g., bone development and leg problems, embryo development, organ development, incubation parameters, chick quality, etc.). The aim of the present study was determine the effects of different eggshell temperatures (low, control, or high) applied between days 10 and 18 of incubation on broiler performance and susceptibility to ascites.

\section{MATERIALS AND METHODS}

The care and use of animals were in accordance with the laws and regulations of Turkey and approved by the Ethical Committee of the Uludağ University (License number 2012-01/02).

A total number of 1800 eggs was obtained from 35-week-old broiler breeders of a commercial Cobb 500 parent stock flock. During the laying period, this flock was reared under standard management conditions in a commercial broiler breeder house. The eggs were stored at $16^{\circ} \mathrm{C}$ and $65 \%$ relative humidity (RH) for two days and warmed to room temperature $\left(22^{\circ} \mathrm{C}\right)$ for $8 \mathrm{~h}$ before setting. All eggs were numbered and weighed $(55-60 \mathrm{~g})$ prior to incubation. Eggs were incubated in a single incubator (1800 capacity egg setter; T2400 C, Cimuka Inc., Ankara, Turkey) at full capacity set at $37.5^{\circ} \mathrm{C}$ and a relative humidity of $55-60 \%$ for the first 10 days of incubation. On d 10 of incubation, eggs were divided into three groups and incubated in fully automated, programmable incubators at full capacity (600 capacity egg setter, 6 trays; T640Cimuka Inc.). In the new incubators, egg trays were placed at same position they occupied in the previous incubator.

Eggshell temperature was daily measured at the equator of the egg using an infrared digital thermometer (Braun, Kronberg, Germany) in 60 eggs per treatment ( 10 eggs per tray) from embryonic day 10 to 18 . These eggs were randomly selected in each tray and individually identified. Set incubator temperatures were not considered. Incubator temperatures were programmed daily based on eggshell temperature. EST was maintained constant between days 10 and 18 for three treatment groups, consisting of low EST (33.3-36.7 $\left.{ }^{\circ} \mathrm{C}\right)$; control EST $\left(37.8-38.2^{\circ} \mathrm{C}\right.$ ), and high EST $\left(38.9-40.0^{\circ} \mathrm{C}\right)$. Because the negative effects of excessive high temperatures on incubation results were the main concern of the present study, a narrower temperature range was applied to high EST treatment. The infrared thermometer was allowed to equilibrate on the floor of an incubator for $10 \mathrm{~min}$ before use. Trays were taken out one by one for temperature measurements, closing the incubator door after each tray was removed.

On d 18, eggs were transferred to a hatcher (1800 capacity egg hatcher T2400 C, Cimuka Inc.). The hatcher was maintained at $36.2^{\circ} \mathrm{C}$ and $70 \% \mathrm{RH}$ until hatching. Between 456 and $518 \mathrm{~h}$ of incubation, the number of chicks hatched was recorded every two hours, and the incubation period of the treatment groups was calculated. After all chicks hatched and their down dried, 30 chicks per group was randomly sampled and weighed using a balance at \pm 0.1 -g precision. Hatchling cloacal temperatures were measured (to the nearest $0.01^{\circ} \mathrm{C}$ ) using a thermocouple thermometer inserted 
into the cloaca immediately after opening hatcher. These chicks were sacrificed by cervical dislocation to determine heart and yolk sac weights. Chicks and yolk sacs were weighed to determine yolk sac free chick weight.

Chicks $(n=720)$ were randomly allocated into treatment groups (low, control, and high EST), and housed in 18 floor pens with a surface area of $2.0 \mathrm{x}$ $2.0 \mathrm{~m}^{2}$, providing six replicates of 40 chicks each at the experimental house of the university. The chicks were weighed using a balance at $\pm 0.1 \mathrm{~g}$ precision at the begining of trial. Wood shavings were used as litter material at a thickness of $7-8 \mathrm{~cm}$.

The chicks were fed a standard pelleted broiler starter diet $(22.5 \% \mathrm{CP}$ and ME $12.8 \mathrm{MJ} / \mathrm{kg}$ of diet) between days 1-14, a grower diet $(22.0 \% \mathrm{CP}$ and ME $13.3 \mathrm{MJ} / \mathrm{kg}$ of diet) between days $15-28$, and a finisher diet $(21.0 \%$ CP and ME $13.5 \mathrm{MJ} / \mathrm{kg}$ of diet) between days 29-42. Feed and water were offered ad libitum throughout the experiment. The chicks were exposed to 24 hours of light in the first week and 23 hours light and 1 hour of darkness until end of the experiment. Room temperature was maintained at $31^{\circ} \mathrm{C}$ at $1 \mathrm{~d}$ of age, and was gradually decreased by $3^{\circ} \mathrm{C} / \mathrm{wk}$ until reaching $20^{\circ} \mathrm{C}$. Room environmental conditions were thereafter maintained at $20^{\circ} \mathrm{C}$ and $50-60 \%$ RH until the end of the experiment. As the present study aimed at evaluating the influence of EST on the incidence of ascites, management and environmental conditions during the growout period were maintained at optimal levels.

Birds and feed were weekly weighed up to the end of trial do determine weight gain and feed intake per pen. Feed converstion ratio was calculated based on the obtained weight gain and feed intake values. Pen mortality was recorded daily during the trial. Birds that died after 14 days of age were submitted to gross examination necropsy for hydropericardium, right ventricular hypertrophy and abdominal fluid accumulation (Shinder et al., 2009).

At slaughter age (day 42), 30 broilers ( 15 males and 15 females) were randomly selected from each treatment group and killed by decapitation. Approximately $1 \mathrm{~mL}$ of blood was collected for the determination of red blood each group was randomly sampled. cell count (RBC), packed cell volume (PCV), and hemoglobin level $(\mathrm{Hb})$, using the standard methods described by Schalm et al. (1975).

The hearts were removed and dissected to obtain heart weight, and right ventricle (RV) and total ventricle (TV) weights to calculate RV:TV ratio as an index of ascites (Huchzermeyer et al., 1988). Birds with $\mathrm{RV}$ :TV values greater than 0.3 were considered to have ventricular hypertrophy (Julian et al., 1989). Broilers found to have abdominal fluid were classified as ascitic (Shinder et al., 2009).

The data were processed with the statistical software package SAS software (SAS Institute, 1989). Duncan's multiple range test was used to compare treatment means. Body weight and feed conversion ratio during the grow-out period were analyzed using the MIXED procedure for repeated measurements, using the EST treatments. Pen was the repeated factor. The measurements taken at slaughter age (i.e., body weight, heart weight, and PCV) were analyzed using the GLM procedure, with EST as treatment. Total mortality and mortality associated with ascites were calculated per pen and analyzed using the Chisquare test, with EST as treatment. Data are presented as means \pm standard error (SE). Differences were considered significant when $\mathrm{P} \leq 0.05$.

\section{RESULTS}

The effects of the different EST treatments on incubation length, hatchling weight, cloacal temperature, residual yolk sac weight, yolk-free BW, and post hatch heart weight are presented in Table 1.

Table 1 - Mean values of incubation length, hatchling weight, cloacal temperature, yolk sac weight and heart weight of broilers according to EST treatment.

\begin{tabular}{lllll}
\hline & Low EST & Control EST & High EST & Probability \\
\hline Incubation Length (h) & 518 & 508 & 482 & \\
Hatchling Weight (g) & $39.2 \pm 1.2^{\mathrm{b}}$ & $42.3 \pm 1.0^{\mathrm{a}}$ & $41.1 \pm 1.0^{\mathrm{b}}$ & 0.015 \\
\hline Measurements & & & & \\
\hline Chick Weight (g) & $39.5 \pm 1.5^{\mathrm{b}}$ & $42.5 \pm 1.1^{\mathrm{a}}$ & $41.0 \pm 1.1^{\mathrm{b}}$ & 0.021 \\
Cloacal temperature $\left({ }^{\circ} \mathrm{C}\right)$ & $38.7 \pm 1.7$ & $39.4 \pm 1.5^{\mathrm{b}}$ & $40.5 \pm 1.0$ & 0.058 \\
Residual yolk sac weight & $5.1 \pm 0.6^{\mathrm{C}}$ & $6.3 \pm 0.9^{\mathrm{B}}$ & $7.7 \pm 1.2^{\mathrm{A}}$ & 0.001 \\
Relative yolk sac weight (\%) & $12.9 \pm 0.7^{\mathrm{C}}$ & $14.7 \pm 0.7^{\mathrm{B}}$ & $18.7 \pm 1.3^{\mathrm{A}}$ & 0.001 \\
Yolk-free BW & $34.5 \pm 1.3^{\mathrm{b}}$ & $36.2 \pm 1.5^{\mathrm{a}}$ & $33.4 \pm 1.2^{\mathrm{b}}$ & 0.036 \\
Relative yolk-free BW (\%) & $87.2 \pm 1.8^{\mathrm{a}}$ & $85.3 \pm 1.6^{\mathrm{a}}$ & $81.3 \pm 1.1^{\mathrm{b}}$ & 0.041 \\
Post-hatch heart weight (g) & $0.35 \pm 0.00^{\mathrm{a}}$ & $0.37 \pm 0.00^{\mathrm{a}}$ & $0.26 \pm 0.00^{\mathrm{b}}$ & 0.014 \\
Relative post-hatch heart weight $(\%)$ & $0.88 \pm 0.01^{\mathrm{a}}$ & $0.84 \pm 0.01^{\mathrm{a}}$ & $0.64 \pm 0.01^{\mathrm{b}}$ & 0.017 \\
\hline
\end{tabular}

a,bMeans in the same row with diferent superscripts are significantly different $(p<0.05)$

A,B Means in the same row with diferent superscripts are significantly different $(p<0.01)$

For chick weight, cloacal temperature, residual yolk weight, yolk-free BW, post-hatch heart weight, a total of 30 chicks from 
Incubation length was 518, 508 and $482 \mathrm{~h}$ in the low, control and high EST groups, respectively. Hatching in high EST group was completed before 26 hours, whereas hatching in low EST group was completed 10 hours after control EST group. The effects of the different EST treatments on hatchling weight was significant. Hatchling weights were 39.54, 42.47 and 41.02 in low, control and high EST groups, respectively. Although cloacal temperature was numerically higher in high EST group, as expected, it was not significantly different among the treatments $(p=0.058)$. Residual yolk sac weight $(\mathrm{g})$ and relative yolk sac weight (\%) were significantly affected by the treatments $(p=0.001)$. The highest residual yolk sac $(p=0.001)$ and relative yolk sac weights $(p=0.001)$ were obtained in high EST group (7.67 $\mathrm{g}$ and $18.70 \%$, respectively. The highest yolk-free BW $(p=0.036)$ was determined in the control EST group $(36.22 \mathrm{~g})$. Relative yolk-free BW (\%) was higher in the low $(87.15 \%)$ and control $(85.28 \%)$ EST groups than in the high (81.30\%) EST group ( $p=0.041)$. Post-hatch heart weights of the low, control and high EST groups were $0.35,0.37$, and $0.26 \mathrm{~g}$, respectively. Post-hatch heart weight was significantly lower in the high EST group ( $p=0.014$ ). Relative post-hatch heart weights (\%) obtained in the low $(0.88 \%)$ and control $(0.84 \%)$ EST groups were similar, but higher in the high (0.64\%) EST group compared with the others $(p=0.017)$.

The effects of the EST treatments on broiler body weight, growth rate, feed intake, cumulative feed intake and feed conversion ratio are presented in Table 2. The initial body weights ( $d 1$ of the grow-out period) of the chicks of the low EST (39.61 g) and high EST groups $(41.04 \mathrm{~g})$ were similar, whereas those of the control EST group (42.38 g) were heavier $(p=0.024)$. There was a significant difference in live weight between weeks 1 and 6 . Chicks of control EST group were consistently heavier during the grow-out period. At 6 weeks of age, the body weights of low, control, and high EST group broilers were 2172.6, 2543.9, $2282.6 \mathrm{~g}$, respectively, and the low EST broilers were lighter than the others $(p=0.001)$. Growth rate was significantly different: between weeks 1 to 3, low EST group broilers grew slower than those of the other groups ( $p<0.05)$, whereas between weeks 4 to 6 , the growth rate of the control EST group broilers increased and was higher compared with the other broilers $(p=0.001)$.

No significant differences in feed intake among treatments were observed during weeks 1 and 2 of the grow-out trial. The highest feed intake was obtained in

Table 2 - Mean values of the body weight, growth rate, feed intake, cumulative feed intake and feed conversion ratio of broilers according to EST treatment.

\begin{tabular}{|c|c|c|c|c|c|c|c|c|}
\hline \multirow{2}{*}{ Variables } & \multirow{2}{*}{ Treatment } & \multirow{2}{*}{$\begin{array}{c}\text { Initial } \\
\text { weight, } g\end{array}$} & \multicolumn{6}{|c|}{ Weeks } \\
\hline & & & 1 & 2 & 3 & 4 & 5 & 6 \\
\hline \multirow{3}{*}{$\begin{array}{l}\text { Body weight, } \\
\text { g/bird }\end{array}$} & Low EST & $39.6 \pm 1.8^{b}$ & $131.1 \pm 3.3^{b}$ & $370.2 \pm 7.7^{b}$ & $727.5 \pm 13.6^{b}$ & $1260.6 \pm 39.7^{b}$ & $1820.0 \pm 52.4^{B}$ & $2172.6 \pm 70.8^{c}$ \\
\hline & Control EST & $42.4 \pm 1.2^{\mathrm{a}}$ & $140.0 \pm 3.4^{\mathrm{a}}$ & $390.6 \pm 8.5^{a}$ & $761.5 \pm 10.5^{a}$ & $1341.4 \pm 53.1^{\mathrm{a}}$ & $2010.8 \pm 71.3^{\mathrm{A}}$ & $2543.9 \pm 100.5^{A}$ \\
\hline & High EST & $41.0 \pm 1.3^{b}$ & $140.8 \pm 2.5^{a}$ & $392.5 \pm 10.3^{a}$ & $765.8 \pm 20.6^{a}$ & $1279.3 \pm 42.6^{b}$ & $1835.3 \pm 60.8^{B}$ & $2282.6 \pm 73.6^{B}$ \\
\hline Probability & & 0.024 & 0.032 & 0.015 & 0.034 & 0.028 & 0.001 & 0.001 \\
\hline \multirow{3}{*}{$\begin{array}{l}\text { Growth rate, } \\
\text { g/bird }\end{array}$} & Low EST & - & $91.5 \pm 2.8^{b}$ & $239.1 \pm 7.9^{b}$ & $357.3 \pm 12.3^{b}$ & $533.1 \pm 22.8^{B}$ & $559.4 \pm 38.5^{B}$ & $352.6 \pm 17.8^{c}$ \\
\hline & Control EST & & $97.6 \pm 3.2^{\mathrm{a}}$ & $250.7 \pm 9.7^{a}$ & $370.9 \pm 13.4^{a}$ & $579.9 \pm 33.2^{\mathrm{A}}$ & $669.4 \pm 46.6^{A}$ & $533.1 \pm 14.6^{A}$ \\
\hline & High EST & - & $99.8 \pm 4.1^{\text {a }}$ & $251.6 \pm 11.3^{a}$ & $373.3 \pm 14.1^{a}$ & $513.5 \pm 24.1^{B}$ & $556.0 \pm 23.6^{B}$ & $447.3 \pm 9.6^{B}$ \\
\hline Probability & & & 0.037 & 0.019 & 0.041 & 0.001 & 0.001 & 0.001 \\
\hline \multirow{3}{*}{$\begin{array}{l}\text { Feed intake, } \\
\text { g/bird }\end{array}$} & Low EST & - & $108.8 \pm 3.4$ & $250.2 \pm 15.2$ & $653.0 \pm 27.8^{a}$ & $800.4 \pm 2.5^{a}$ & $1304.2 \pm 57.3^{b}$ & $933.5 \pm 47.1^{b}$ \\
\hline & Control EST & & $106.5 \pm 3.2$ & $258.5 \pm 14.3$ & $579.1 \pm 21.4^{c}$ & $730.2 \pm 37.6^{b}$ & $1507.0 \pm 74.5^{a}$ & $1089.6 \pm 55.0^{a}$ \\
\hline & High EST & - & $104.9 \pm 2.3$ & $262.2 \pm 16.7$ & $610.3 \pm 19.2^{b}$ & $805.6 \pm 44.4^{a}$ & $1319.4 \pm 62.4^{b}$ & $1085.8 \pm 52.2^{\mathrm{a}}$ \\
\hline Probability & & & 0.602 & 0.326 & 0.044 & 0.027 & 0.036 & 0.042 \\
\hline \multirow{3}{*}{$\begin{array}{l}\text { Cumulative feed } \\
\text { intake, } g\end{array}$} & Low EST & - & - & $358.9 \pm 17.3$ & $1011.9 \pm 85.3$ & $1812.3 \pm 95.5^{a}$ & $3116.3 \pm 175.9$ & $4049.8 \pm 188.3$ \\
\hline & Control EST & & & $365.0 \pm 14.8$ & $944.1 \pm 82.5$ & $1674.3 \pm 55.7^{b}$ & $3082.0 \pm 182.2$ & $4271.6 \pm 221.2$ \\
\hline & High EST & - & - & $367.1 \pm 15.5$ & $977.4 \pm 76.4$ & $1783.0 \pm 66.3^{a}$ & $3102.5 \pm 148.6$ & $4188.3 \pm 193.2$ \\
\hline Probability & & & & 0.487 & 0.321 & 0.017 & 0.968 & 0.782 \\
\hline \multirow{3}{*}{$\begin{array}{l}\text { Feed conversion } \\
\text { ratio }\end{array}$} & Low EST & - & $0.83 \pm 0.10$ & $0.97 \pm 0.11$ & $1.39 \pm 0.12^{\mathrm{a}}$ & $1.44 \pm 0.12^{\mathrm{a}}$ & $1.71 \pm 0.13^{a}$ & $1.86 \pm 0.17^{A}$ \\
\hline & Control EST & & $0.77 \pm 0.09$ & $0.93 \pm 0.09$ & $1.23 \pm 0.10^{b}$ & $1.25 \pm 0.10^{b}$ & $1.58 \pm 0.11^{b}$ & $1.68 \pm 0.14^{\mathrm{B}}$ \\
\hline & High EST & - & $0.75 \pm 0.07$ & $0.94 \pm 0.12$ & $1.28 \pm 0.10^{\mathrm{ab}}$ & $1.39 \pm 0.11^{\mathrm{a}}$ & $1.69 \pm 0.11^{a}$ & $1.83 \pm 0.15^{\mathrm{A}}$ \\
\hline Probability & & & 0.673 & 0.721 & 0.018 & 0.026 & 0.041 & 0.001 \\
\hline
\end{tabular}

a,bMeans in the same row with diferent superscripts are significantly different $(p<0.05)$

A,BMeans in the same row with diferent superscripts are significantly different $(p<0.01)$ 
the low EST group in week 3, in the low and high EST groups in week 4, in the control EST group in week 5, and in the control and high groups in week $6(p<0.05)$. The effects of EST on the cumulative feed intake were not significant during the experiment, except for week 4, when the control EST group presented lower cumulative feed intake relative to the other groups $(p=0.017)$.

There were no significant differences in feed conversion ratio between experimental weeks 1 and 2 . Feed conversion ratio was similar in both the low and high EST groups at 3,4 , and 5 weeks of age $(p<0.05)$. During the 6-week life span, the low (1.86) and high (1.83) EST groups presented significantly worse feed conversion ratio relative to the EST control group (1.68) $(p=0.001)$.

Total mortality between 1 and 42 days of age was not different among the EST treatments (ChiSquare $=1.634, p=0.422$ ). However, numerically lower mortality ratio was observed in the EST control group. Mortality due to ascites was not observed in the high EST group, and only one bird died of ascites in the other groups (Table 3).

Table 3 - Mortality due to other causes and mortality due to ascites of broilers according to EST treatment.

\begin{tabular}{lcccc}
\hline \multirow{2}{*}{ Treatments } & \multicolumn{4}{c}{ Distribution of the causes of mortality } \\
\cline { 2 - 5 } & \multicolumn{3}{c}{ Other than ascites, \% } & Due to ascites, \% \\
Low EST & $1-7 \mathrm{~d}$ & $8-42 \mathrm{~d}$ & $1-42 \mathrm{~d}$ & $8-42 \mathrm{~d}$ \\
Control EST & $0.42(1 / 240)$ & $0.42(1 / 240)$ & $2.08(5 / 240)$ & $0.42(1 / 240)$ \\
High EST & $2.91(7 / 240)$ & $0.83(2 / 240)$ & $1.25(3 / 240)$ & $0.42(1 / 240)$ \\
Chi-Square & 4.576 & - & $2.91(7 / 240)$ & - \\
Probability & 0.101 & 0.366 & 1.634 & 1.003 \\
\hline
\end{tabular}

Numbers in the parentheses are no. of dead birds/total no. of birds

The mean hematological values of the EST groups at slaughter age are presented in Table 4. The high EST group presented PCV and RBC were higher in the than in the other groups $(p=0.001)$, and the $\mathrm{Hb}$ level was lower in the control EST group than in other groups $(p=0.018)$.

Table 4 - Mean haematological values of broilers at slaugher according to EST treatment.

\begin{tabular}{lcccc}
\hline $\begin{array}{l}\text { Blood } \\
\text { Parameters }\end{array}$ & Low EST & Control EST & High EST & Probability \\
PCV, \% & $30.9 \pm 2.62^{\mathrm{B}}$ & $29.6 \pm 2.01^{\mathrm{C}}$ & $34.5 \pm 1.04^{\mathrm{A}}$ & 0.001 \\
$\mathrm{Hb}, \mathrm{g} / \mathrm{dL}$ & $9.1 \pm 0.17^{\mathrm{a}}$ & $8.8 \pm 0.14^{\mathrm{b}}$ & $9.0 \pm 0.20^{\mathrm{a}}$ & 0.041 \\
$\mathrm{RBC} \mathrm{M} / \mathrm{mm}^{3}$ & $2.2 \pm 0.26^{\mathrm{B}}$ & $2.0 \pm 0.17^{\mathrm{C}}$ & $2.4 \pm 0.20^{\mathrm{A}}$ & 0.001 \\
\hline
\end{tabular}

a,bMeans in the same row with diferent superscripts are significantly different $(p<0.05)$ A,BMeans in the same row with diferent superscripts are significantly different $(p<0.01)$ For blood parameters, a total of 30 broilers from each group were sampled.
Mean slaughter weight and heart parameters are presented in Table 5. A significant difference was observed for slaughter weight and relative heart weight among treatments $(p=0.001)$. Relative heart weights of the low, control and high EST groups were $0.46,0.40$, and $0.37 \%$, respectively. The difference in the RV weights was not significant between the groups. The left ventricle + septum and total ventricle (TV) weights were lower in the high EST group $(p=0.001)$, but similar in the low and control EST groups. The RV:TV ratios of the low, control, and high EST groups were 0.27, 0.28, $0.33 \%$, respectively, and significantly higherin the high EST group compared with the others $(p=0.001)$. During slaughter, abdominal fluid accumulation was observed in seven birds of the high EST group, but not in the low and control EST groups.

\section{DISCUSSION}

Commercial hatcheries typically apply incubation length of approximately 505 hours. Broiler chicks hatch in a time range of 480 to 510 hours. Factors such as breeder age, egg weight, hatchable egg storage conditions, season (Wilson, 1991), and incubation temperature (French, 1994; Wilson, 1991) influence total incubation time. Vieira et al. (2005) observed that $90 \%$ of eggs hatched at 485 hours and that the hatchlings remained for 19 hours in the hatcher to allow the remaining $10 \%$ to hatch. In the present study, hatching in high EST group was completed before 26 hours, although hatching in low EST group was completed only after 10 hours than control EST group.

Day-old chick weight includes the actual chick weight and the weight of the residual yolk sac (Tullett \& Burton, 1982). Residual yolk sac comprises approximately $14 \%$ of the chick's body weight at the time of hatching (Mikec et al., 2006). A large amount of residual yolk sac present at hatch indicates that this energy source was underutilized during incubation and that the chick is less developed. The quality of the day-old chick is important for a good start of the chick and, consequently, for better overall performance of the broiler (Meijerhof, 2009a). Although the EST group presented the highest residual yolk sac weight and relative yolk sac weight, the lowest post-hatch heart weight and relative post-hatch heart weight, yolkfree BW and post-hatch heart weight were highest in control EST group. Chick hatch weight was different among EST groups and its variability may be explained by the differences in residual yolk sac weights observed in the present study. 
Table 5 - Mean heart weights and parameters of broilers at slaugher according to EST treatment.

\begin{tabular}{lcccc}
\hline Heart Parameters & Low EST & Control EST & High EST & Probability \\
Slaughter weight, g/ bird & $2184.5 \pm 71.2^{\mathrm{C}}$ & $2566.4 \pm 102.2^{\mathrm{A}}$ & $2302.2 \pm 75.6^{\mathrm{B}}$ & 0.001 \\
Relative heart weight (\%) & $0.46 \pm 0.02^{\mathrm{A}}$ & $0.40 \pm 0.02^{\mathrm{B}}$ & $0.37 \pm 0.01^{\mathrm{C}}$ & 0.001 \\
Right ventricle (RV) weight, g/bird & $2.69 \pm 0.56$ & $2.9 \pm 0.71$ & $2.8 \pm 0.41$ & 0.646 \\
Left ventricle + septum weight, g/ bird & $7.4 \pm 1.47^{\mathrm{A}}$ & $7.3 \pm 1.03^{\mathrm{A}}$ & $5.8 \pm 1.52^{\mathrm{B}}$ & 0.001 \\
Total ventricle (TV) weight, g/ bird & $10.0 \pm 1.80^{\mathrm{A}}$ & $10.2 \pm 1.3^{\mathrm{A}}$ & $8.6 \pm 1.61^{\mathrm{B}}$ & 0.001 \\
RV:TV Ratio & $0.27 \pm 0.04^{\mathrm{B}}$ & $0.28 \pm 0.05^{\mathrm{B}}$ & $0.33 \pm 0.04^{\mathrm{A}}$ & 0.001 \\
\hline
\end{tabular}

$a, b$ Means in the same row with diferent superscripts are significantly different $(p<0.05)$

$A, B$ Means in the same row with diferent superscripts are significantly different $(p<0.01)$

For heart parameters, a total of 30 broilers from each group were sampled.

Changes in the EST clearly affected the chick body weights at hatch. The initial body weights of the low and high EST groups were similar, but the control group chicks were heavier. Shim \& Pesti (2011) also reported that changes in the incubation temperature of as little as $1^{\circ} \mathrm{C}$ on embryonic days 4 to 7 affected chick body weight at hatch, as shown by hatching chick weights of $48.98,49.57$ and $50.56 \mathrm{~g}$ obtained with low $\left(36.5^{\circ} \mathrm{C}\right)$, control $\left(37.5^{\circ} \mathrm{C}\right)$, and high $(38.5$ ${ }^{\circ} \mathrm{C}$ ) incubation temperatures, respectively. On the other hand, Christina et al. (2007) found that high incubation temperatures increase chick initial body weight. In contrast to our findings, Yalcin et al. (2010) reported that chick weights are not influenced by incubation temperature. The results of the present study generally agree with various studies reporting that incubation temperatures influence broiler performance (Shafey, 2004; Lourens et al., 2005, 2007; Meijerhof, 2009a). Hulet et al. (2007) demonstrated that different eggshell temperatures significantly affected the feed conversion ratio of 44 -d-old broilers, with values of 1.91, 1.86, and 1.87 for eggs incubated at $37.5,38.6$ and $39.7^{\circ} \mathrm{C}$, respectively.

Ascites has become a major cause of mortality in modern broiler production worldwide (Wideman \& French, 2000; Balog, 2003; Pakdel et al., 2005; Pavlidis et al., 2007; Arce-Menocal et al., 2009; Hassanzadeh et al., 2010). Many difficulties in broiler production, such as ascites, are related with cardiovascular development and function problems (Leksrisompong et al., 2007). Differences in embryo temperatures result in differences in the development of specific organs, such as the heart muscle both in embryos and chickens (Wineland et al., 2000a, 2000b; Shafey, 2004; Leksrisompong et al., 2007; Lourens et al., 2007). The reduced heart weights at hatch due to higher EST may increase the susceptibility to and the incidence of metabolic disorders related with cardiovascular development later in life, such as ascites (Wineland et al., 2000a, Leksrisompong et al., 2007). In the present study, the
TV ratio was lower in the high EST group than in the other groups. The lack of TV development at six weeks of age may be related with embryo development. This notion is supported by the lower heart weight at hatch observed in the high EST group compare with other groups. The heart weights at hatch in the control and low EST groups were $28 \%$ and $26 \%$ lower compared with that obtained in the high EST group, respectively.

It was previously assumed that the high susceptibility to ascites of modern broilers was linked to their high growth rate (Maxwell et al., 1990; Robinson et al., 1992; Acar et al., 1995; Balog et al., 2000). However, some authors suggest that the growth rate per se is not related to ascites (Balog et al., 2001). In the present study, the control EST group presented the highest growth rate, but did not show signs of ascites, and therefore support the suggestion of Balog et al. (2001).

The RV:TV ratio was higher in the high EST group than in the other groups. Molenaar et al. (2011) found that the ratio between the right and total ventricle mass of broilers was $1.1 \%$ higher in the high EST group $\left(38.9^{\circ} \mathrm{C}\right)$ compared with the normal EST treatment $\left(37.8^{\circ} \mathrm{C}\right)$ at slaughter age.

Lubritz \& McPherson (1994) found that a high embryo temperature had a negative effect on the pulmonary vascular capacity, increasing oxygen metabolic demand, and consequently to the development of ascites. Studies have shown that due to increased $\mathrm{O}_{2}$ requirement, broilers susceptible to ascites present higher $\mathrm{O}_{2}$ carrying capacity, blood viscosity, number of red blood cells, hematocrit value, and a lower relative heart weight than normal broilers (Scheele et al., 1991; Lubritz \& McPherson, 1994; Decuypere et al., 2000). High hematocrit values increase cardiac output, pulmonary hypertension, and right ventricle hypertrophy. As a result of increasing intravascular pressure, fluid accumulation in the abdominal cavity and pericardium can occur (Decuypere et al., 2000), and birds die due to ascites. The results of the present study support 
these findings. In this study, deaths due to ascites were not observed in the high EST group; however, the high hematocrit, RBC and RV/TV values and the abdominal fluid accumulation observed in seven birds at slaughter, indicated higher ascites susceptibility in this group.

In conclusion, incubation length, yolk sac absorbtion, residual yolk sac weight, yolk-free chick weight, and post-hatch performance are affected by small changes in the EST. Total mortality and mortality due to ascites were generally very low in all groups. Such low mortality may have resulted from optimal management and climate conditions. Heart and blood parameters and observed abdominal fluid accumulation at slaughter age show that, in cases of inadequate housing conditions, such as sub-optimal ventilation and temperature control, and older slaughter ages, mortality due to ascites in high EST groups will presumably be very high.

\section{ACKNOWLEDGEMENTS}

This study was financially supported by the Scientific Research Project Council Of Uludag University (Project Number KUAP(Z)-2012/14).

\section{REFERENCES}

Acar N, Sizemore FG, Leach GR, Wideman FFJ, Owen RL, Barbato GF. Growth of broiler chickens in response to feed restriction regimes to reduce ascites. Poultry Science 1995;74:833-843.

Altan O, Sahan U, Ipek A, Aydin C, Bayraktar H. Effects of oxygen supplementation on embryonic survival, haematological parameters and plasma glucose level of broiler chicks. Archiv der Geflugelkunde 2006;70(2):64-68.

Arce-menocal J, Avila-Gonzalez E, Lopez-Coello C, Garibay-Torres L, MartinezLemus LA. Body weight, feed-particle size, and ascites incidence revisited. Journal of Applied Poultry Research 2009;18:465-471.

Balog JM, Anthony NB, Cooper MA, Kidd BD, Huff GR, Huff WE, Rath NC. Ascites syndrome and related pathologies in feed restricted broilers raised in a hypobaric chamber. Poultry Science 2000;79:318-323.

Balog JM, Anthony NB, Kidd BD, Liu X, Cooper MA, Huff GR, Huff WE, Widemann RF, Rath NC. Genetic selection of broiler lines that differ in their ascites susceptibility 2. response of the ascites lines to cold stress and bronchus occlusion. Proceedings of the 13th European Symposium on Poultry Nutrition; 2001; Blankenberghe. Belgium. p. 329-330.

Balog JM. Ascites syndrome (pulmonary hypertension syndrome) in broiler chickens: Are we seeing the light at the end of the tunnel? Avian and Poultry Biology Reviews 2003;14:99-126.

Christina LH, Biggy HS, Stickland NC. In ovo temperature manipulation influences embryonic motility and growth of limb tissues in the chick (Gallus gallus). The Journal of Experimental Biology 2007;210:26672675

Coleman MA, Coleman GE. Ascites control through proper hatchery management. Misset World Poultry 1991; 7:33-35.
Decuypere E, Buyse J, Buys N. Ascites in broiler chickens: Exogenous and endogenous structural and functional causal factors. World's Poultry Science Journal 2000:56:367-377.

French NA. Effect of incubation temperature on the gross pathology of turkey embryos. British Poultry Science 1994;35:363-371.

French NA. Effect of short periods of high incubation temperature on hatchability and incidence of embryo pathology of turkey eggs. British Poultry Science 2000;41:377-382.

Hassanzadeh M, Maddadi MS, Mirzaie S, Assasie K, Moayyedian H. Partial pressure of carbon dioxide in the venous blood of young birds as a predictor of ascites susceptibility in broiler chickens. Acta Veterinaria Hungarica 2010;58:221-230.

Huchzermeyer FW, Deruyck AMC, Van Ark H. Broiler pulmonary hypertension syndrome, III. Commercial broiler strains differ in their susceptibility. The Onderstepoort Journal of Veterinary Research 1988:55:5-9.

Hulet R, Gladys G, Hill D, Meijerhof R, Elshiekh T. Influence of eggshell embryonic incubation temperature and broiler breeder flock age on posthatch growth performance and carcass characteristics. Poultry Science 2007;86:408-412.

Ipek A, Sahan U. Effects of cold stress on broiler performance and ascites susceptibility. Asian-Australian Journal of Animal Science 2006;19(5):734-738.

Joseph NS, Lourens A, Moran JET. The effects of suboptimal eggshel temperature during incubation on broiler chick quality, live performance, and further processing yield. Poultry Science 2006;85:932-938.

Julian RJ, McMillan I, Aquinton M. The effect of cold and dietary energy on right ventricular hypertrophy, right ventricular failure and ascites in meat type chickens. Avian Pathology 1989;18:675-684.

Leksrisompong N, Romero-Sanchez H. Plumstead PW, Brannan KE, Brake J. Broiler Incubation. 1. Effect of elevated temperature during late incubation on body weight and organs of chicks. Poultry Science 2007:86:2685-2691.

Leksrisompong N, Romero-Sanchez H, Plumstead PW, BrannanKE, Yahav $S$, Brake J. Broiler incubation. 2.Interaction of incubation and brooding temperatures on broiler feed intake and growth. Poultry Science 2009;88:1321-1329

Lourens A, Brand HVD, Meijerhof R, Kemp B. Effect of eggshell temperature during incubation on embryo development, hatchability, and posthatch development. Poultry Science 2005;84:914-920.

Lourens A, Brand HVD, Heetkamp MJW, Meijerhof R, Kemp B. Effects of eggshell temperature and oxygen concentration on embryo growth and metabolism during incubation. Poultry Science 2007;86:2194-2199.

Lubritz DL, McPherson BN. Effect of genotype and cold stress on incidence of ascites in cockerels. Journal of Applied Poultry Research 1994;3:171178.

Maxwell MH, Spence S, Robertson GW, Mitchell MA. Heamatological and morphological responses of broiler chicks to hypoxia. Avian Pathology 1990;19:23-40

Meijerhof R. The influence of incubation on chick quality and broiler performance. 20 ${ }^{\text {th }}$ Annual Australian Poultry Science Symposium; 2009a; New South Wales, Sydney. Australia. p.167-176.

Meijerhof R. Incubation principles: what does the embryo expect from us? $20^{\text {th }}$ Annual Australian Poultry Science Symposium; 2009b; New South Wales, Sydney. Australia. p. 106-111. 
Mikec M, Bidin Z, Valentic A, Savic V, Zelenika TA, Raguz-Duric R, Novak IL, Balenovic M. Influence of environmental and nutritional stressors on yolk sac utilization, development of chicken gastrointestinal system and its immune status. World's Poultry Science Journal 2006;62:31-40.

Molenaar R, Hulet R, Meijerhof R, Maatjens CM, Kemp B, Brand HVD. High eggshell temperatures during incubation decrease growth performance and increase the incidence of ascites in broiler chickens. Poultry Science 2011;90:624-632.

Pakdel A, Bijma P, Ducro BJ, Bovenhuis H. Selection strategies for body weight and reduced ascites susceptibility in broilers. Poultry Science 2005;84:528-535

Pavlidis HO, Balog JM, Stamps LK, Hughes JJD, Huff WE, Anthony NB. Divergent selection for ascites incidence in chickens. Poultry Science 2007:86:2517-2529.

Robinson FE, Classen HL, Hanson JA, Onderka DK. Growth performance, feed efficiency and the incidence of skeletal and metabolic disease in full fed and feed restricted broiler and roaster chickens. Journal of Applied Poultry Research 1992;1:33-41.

Sahan U, Ipek A, Altan O, Yilmaz DB. Effects of oxygen supplementation during the last stage of incubation on broiler performance, ascites susceptibility and some physiological traits. Animal Research 2006;55:145-152.

SAS Institute. A user's guide to SAS. Cary;1989.

Schalm OW, Jain NC, Caroll EJ. Veterinary haematology. 3rd ed. Philadelphia: Lea and Febiger; 1975. p. 15-81.

Scheele CW, Wit W, Frankenhuis MT, Vereijken PFG. Ascites in broilers. 1. Experimental factors evoking symptoms related to ascites. Poultry Science 1991;70:1069-1083.

Shafey TM. Effect of lighted incubation on embryonic growth and hatchability performance of two strains of layer breeder eggs. British Poultry Science 2004;45:223-229.

Shim MY, Pesti GM. Effects of incubation temperature on the bone development of broilers. Poultry Science 2011;90:1867-1877.

Shinder D, Rusal M, Giloh M, Yahav S. Effect of repetitive acute cold exposures during the last phase of broiler embryogenesis on cold resistance through the life span. Poultry Science 2009;88:636-646.
Tullett SG, Burton FG. Factors affecting the weight and water status of the chick at hatch. British Poultry Science 1982;23:361-369.

Vieira SL, Almeida JG, Lima AR, Conde ORA, Olmos AR. Hatching distribution of eggs varying in weight and breeder age. Brazilian Journal of Poultry Science 2005;7:73-78.

Wideman RFJ, French $\mathrm{H}$. Ascites resistance of progeny from broiler breeders selected for two generations using chronic unilateral pulmonary artery occlusion. Poultry Science 2000;79:396-401.

Wideman RF. Pathophysiology of heart/lung disorders: pulmonary hypertension syndrome in broiler chickens. World's Poultry Science Journal 2001;57(3):289-307.

Willemsen $\mathrm{H}$, Kamers B, Dahlke F, Han H, Song Z, Ansari PZ, Tona K, Decuypere E, Everaert N. High and low temperature manipulation during late incubation: Effects on embryonic development, the hatching process, and metabolism in broilers. Poultry Science 2010;89:26782690.

Wilson HR. Interrelationships of egg size, chick size, posthatching growth and hatchability. World's Poultry Science Journal 1991;47:5-20.

Wineland MJ, Mann KM, Fairchild BD, Christensen VL. Effect of high and low incubator temperatures at different stages of development upon the broiler embryo. International Poultry Scientific Forum; 2000a; Atlanta, Georgia. Estados Unidos. Abstract 180.

Wineland MJ, Mann KM, Fairchild BD, Christensen VL. Effect of different setter and hatcher temperatures upon the broiler embryo. Poultry Science 2000b;79(Suppl. 1):181.

Yahav S, Straschnow A, Plavnik I, Hurwitz S. Blood system response of chickens on changes in environmental-temperature. Poultry Science 1997;76:627-633.

Yalcin S, Babacanoğlu E, Guler HC, Akşit M. Effects of incubation temperature on hatching and carcass performance of broilers. World's Poultry Science Journal 2010;66:87-94

Yersin AG, Huff WE, Kubena LF, Elissalde MH, Harvey RB, Witzel DA. Changes in hematological, blood gas, and serum biochemical variables in broilers during exposure to simulated high altitude. Avian Disease 1992;36:189-196 